\title{
Modeling the Thermal Behavior of a Surface-micromachined Linear-displacement Thermomechanical Microactuator
}

\author{
Christian D. Lott \\ Timothy W. McLain \\ mclain@byu.edu \\ John N. Harb \\ john_harb@byu.edu \\ Larry L. Howell \\ Ihowell@byu.edu
}

Brigham Young University, christian.d.lott@l-3com.com

Follow this and additional works at: https://scholarsarchive.byu.edu/facpub

Part of the Mechanical Engineering Commons

\section{Original Publication Citation}

Lott, C.D., McLain, T.W., Harb, J.N., and Howell, L.L., â€œModeling the Thermal Behavior of a Surface-micromachined Linear-displacement Thermomechanical Microactuator,â€ Sensors \& Actuators: A. Physical, Vo1. 11, Nos. 1-2, pp. 239-25, 22.

\section{BYU ScholarsArchive Citation}

Lott, Christian D.; McLain, Timothy W.; Harb, John N.; and Howell, Larry L., "Modeling the Thermal Behavior of a Surface-micromachined Linear-displacement Thermomechanical Microactuator" (2002). Faculty Publications. 533.

https://scholarsarchive.byu.edu/facpub/533

This Peer-Reviewed Article is brought to you for free and open access by BYU ScholarsArchive. It has been accepted for inclusion in Faculty Publications by an authorized administrator of BYU ScholarsArchive. For more information, please contact ellen_amatangelo@byu.edu. 


\title{
Modeling the Thermal Behavior of a Surface-micromachined Linear-displacement Thermomechanical Microactuator
}

\author{
C.D. Lott ${ }^{*}$ \\ T.W. McLain ${ }^{*}$ \\ J.N. Harb ${ }^{\dagger}$ \\ L.L. Howell ${ }^{*}$ \\ *Department of Mechanical Engineering \\ ${ }^{\dagger}$ Department of Chemical Engineering \\ Brigham Young University \\ Provo, Utah 84602
}

\begin{abstract}
Thermomechanical microactuators possess a number of desirable attributes including ease of fabrication and large force and displacement capabilities relative to other types of microactuators. These advantages provide motivation for improving thermomechanical microactuator designs that are more energy efficient and thus better suited for low-power applications. To this end, this paper describes the development and experimental validation of a finite-difference thermal model of a thermomechanical in-plane microactuator (TIM). Comparisons between the model and experimental results demonstrate the importance of including the temperature dependence of several parameters in the model. Strategies for reducing the power and energy requirements of the TIM were investigated using model simulations as a guide. Based on design insights gained from the model, the energy efficiency of the TIM has been improved significantly by operating in a vacuum environment and providing short-duration, high-current pulse inputs. These improvements have been validated experimentally.
\end{abstract}

\section{INTRODUCTION}

Microactuators for microelectromechanical systems (MEMS) have been developed in a wide variety of forms. The most common modes of actuation are based on piezoelectric, thermal-mechanical, magnetic, or electrostatic effects at the device level. A judicious choice for an appropriate actuation strategy must consider the system-level requirements for performance. Performance specifications can include power, energy consumption, 
displacement, force, and size. While certain system-level tasks may be dictated by only one of these specifications, most will be concerned with more. This is surely the case with recent micro-autonomous system developments [1].

Polysilicon electrothermal microactuators have demonstrated significant promise in MEMS applications because of their large displacement and force output capabilities combined with their ability to be driven at CMOS compatible voltages and currents. Because of these benefits, this type of actuation is an attractive choice for system-level design despite significant inefficiencies. Early work on MEMS electrothermal actuators was done by Guckel et al. [2] who developed a metal flexure actuator using the SLIGA process. Comtois and co-workers [3] developed a pseudo-bimorph microactuator with a similar topology, but from polysilicon. The development of a comprehensive finiteelement thermal model of a polysilicon pseudo-bimorph design was recently published by Mankame and Ananthasuresh [4]. In [5], Moulton and Ananthasuresh provide an overview of electro-thermal-compliant (ETC) actuation for MEMS, and discuss analysis and design issues for ETC devices. Bent-beam electrothermal actuators have been developed and modeled by Que et al. In [6], both single and cascaded arrangements of bent-beam actuators are modeled and analyzed. Park et al. [7] employ bent-beam actuators to drive both rotary displacement devices and long-throw linear inchworm mechanisms. Topology optimization techniques have been applied to the design of electrothermal microactuators by Sigmund [8] and Jonsmann et al. [9].

In general, thermal actuators operate by tailoring the geometry of specific parts of a device so that they expand as external heating or an electrical current is applied. Electrothermal actuators consume considerably more power than comparable electrostatic or piezoelectric actuation strategies. The need exists, therefore, to understand how to best raise the temperature in these microactuators to obtain a desired deflection using minimal power and energy. To design effectively at the system level, the power to hold the actuator at a steady position and the energy expenditure required to get it there must be identifiable. A dynamic model of the electrothermal transient is required to quantify the energy consumed to reach steady state. 


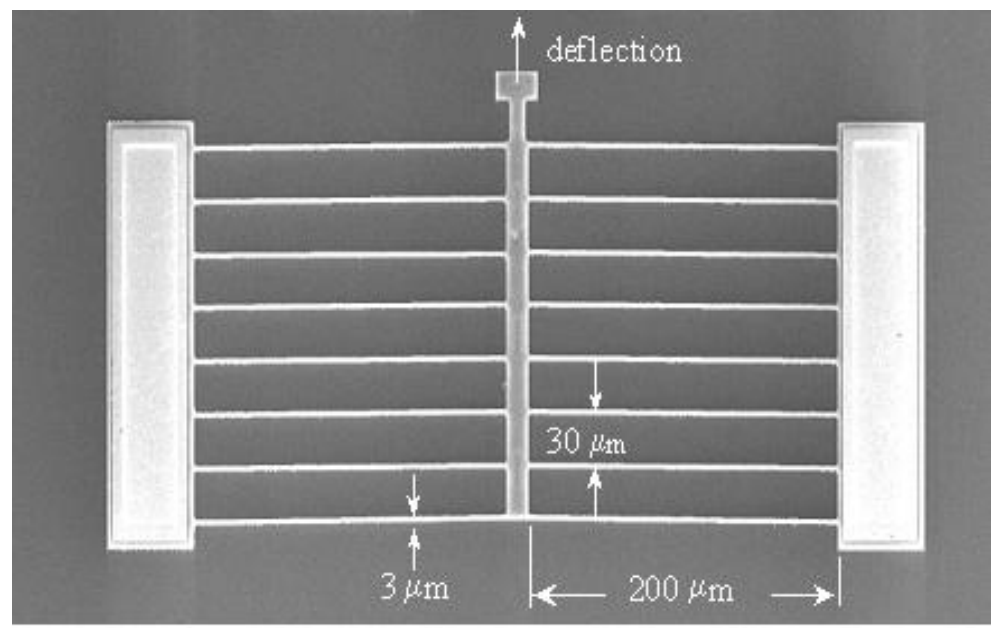

Figure 1: Thermomechanical In-plane Microactuator (TIM).

This paper presents research on the modeling of a Thermomechanical In-plane Microactuator (TIM) [10]. This microactuator can be fabricated with any process that allows a single releasable material layer to be placed on an electrically insulating substrate. The actuators modeled and tested here were designed and fabricated using the Multi-User MEMS Processes (MUMPs) [11]. As Figure 1 shows, the basic TIM design consists of a moveable shuttle connected to electrical contact pads anchored on the substrate by slender thermal expansion legs. As a voltage difference is applied across the contact pads, current flows through the legs and the center shuttle. The high current density in the legs causes ohmic heating and thermal expansion. The shuttle serves as a geometric constraint, helps to amplify the linear motion, and localizes the output force. The legs are connected to the shuttle at a slight inclination angle so that their expansion causes a linear motion of the shuttle in the desired direction.

The TIM has the benefit of being extremely flexible in design. As the length of the expansion legs is increased, the available displacement also increases. As the length of the expansion legs is decreased, the TIM is made more rigid in buckling, thus enhancing the available output force. The available actuation force also increases linearly with the number of leg pairs. The effect of these design changes on the power requirements of the TIM, however, is not immediately identifiable. In this paper, a mathematical model is 

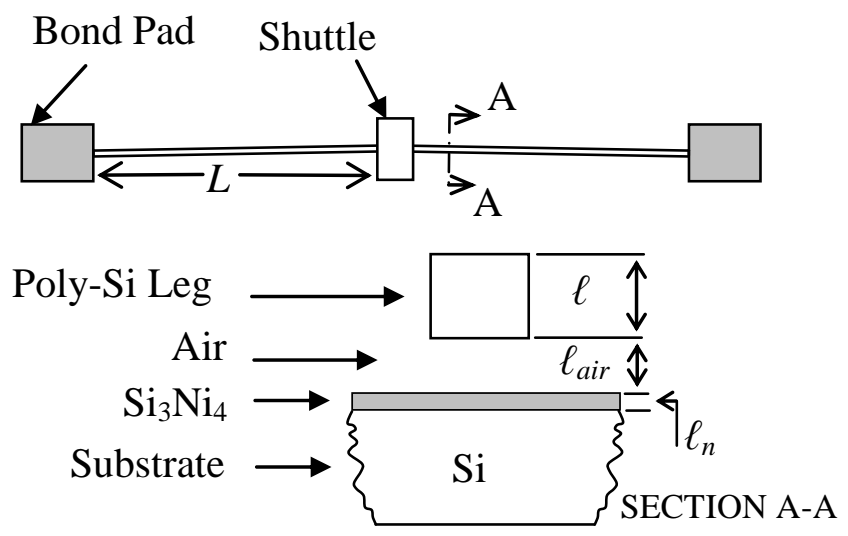

Figure 2: Schematic of TIM device and leg cross-section.

used to simulate the power and energy consumption of the TIM under both steady-state and transient conditions, with the objective of improving its efficiency.

\section{ELECTROTHERMAL MODEL DEVELOPMENT}

To avoid separately modeling the entire actuator for each particular configuration of a TIM, the electrothermal model presented here is based on a single leg-pair. The single leg-pair model captures the functionality of the full TIM device and provides a significant reduction in model complexity. A schematic of a single leg-pair is shown in Figure 2. This component of the actuator contains all the design parameters necessary for the simulation of a complete TIM. The portion of the TIM modeled for simulation consists of a shuttle suspended above the substrate by two legs, which are anchored by bond pads to the substrate. In modeling the heat flow from the microactuator, a one-dimensional treatment for heat conduction in the legs is used since the length dimension is much larger than any dimension of the cross-section.

The heat transfer of a full TIM, such as that shown in Figure 1, can be modeled using a single-leg-pair model under the assumption that each pair of legs is thermally independent. For the spacing of the legs shown in Figure 1, the validity of this assumption has been verified with commercial finite-element code (ANSYS 5.5). Following common practice, a conduction shape factor that accounts for conduction from the sides of the legs to the substrate and environment is included for more accurate modeling $[12,13]$. 
To set up the finite-difference model, the device in Figure 2 was divided into discrete volume elements. By applying an energy balance to a control volume around each element, a state equation is formulated for each. When solved, the set of equations for all elements produces the nodal temperatures throughout the body. Based on an energy balance, the following state equation is obtained for the $i^{\text {th }}$ element

$$
q_{\Omega}+q_{\text {cond }}+q_{\text {rad }}+q_{\text {cond }, i-1}+q_{\text {cond }, i+1}=q_{s t},
$$

where $q_{\Omega}$ is the rate of energy generated in element $i$ by ohmic heating, $q_{\text {cond }}$ models conduction to the substrate, and $q_{\text {rad }}$ models radiation to the surroundings. The conduction to element $i$ from adjoining elements is modeled by the $q_{c o n d, i-1}$ and $q_{c o n d, i+1}$ terms. The net rate of change of the internal energy storage within the element is modeled by $q_{s t}$. The contribution of free convection to the substrate and the surroundings has been found to be small relative to conductive and radiative heat transfer modes $[12,14]$. Because the air gap between the TIM and the substrate is thin $(2 \mu \mathrm{m})$, the flow of air underneath the TIM is negligible. This supports the use of a conductive model for the air gap, rather than a convective model.

Each of these energy terms can be determined from straightforward physical relationships. Ohmic heating can be calculated from the input current and material resistivity, $\rho_{r}(T)$, as

$$
q_{\Omega}=J^{2} \rho_{r}(T) \Delta V_{i}
$$

where $J$ is the current density input to the system and $\Delta V_{i}$ is the element volume. Conduction to the substrate is modeled by the expression

$$
q_{\text {cond }}=\frac{S A_{u}}{G_{u}} \mathbf{T}_{\text {sub }}-T_{i}(j)_{-}^{-},
$$

where $T_{\text {sub }}$ is the temperature of the substrate (assumed constant) and $T_{i}(j)$ is the temperature of the $i^{\text {th }}$ node at the $j^{\text {th }}$ time increment. $A_{u}$ represents the surface area of the element facing the substrate. $S$ is a shape factor that accounts for conduction from the vertical faces of the element to the substrate. The expression used for the shape factor was developed in [12], and is based on a two-dimensional numerical heat transfer model: 


$$
S=\frac{\ell}{w}\left(\frac{2 \cdot \ell_{a i r}}{\ell}+1\right)+1 .
$$

The parameter $\ell$ represents the height of the element, $w$ is the width, and $\ell_{\text {air }}$ is the height of the air gap between the leg and the substrate.

From the cross-section in Figure 2, it is evident that the heat path to the substrate is through the air and an electrically insulated layer of silicon nitride into the substrate. These layers act as three thermal paths in series, allowing $G_{u}$ to be defined as

$$
G_{u}=\frac{\ell_{a i r}}{k_{a i r}}+\frac{\ell_{n}}{k_{n}}+\frac{\ell_{s}}{k_{s}},
$$

where $\ell_{n}$ is the height of the $\mathrm{Si}_{3} \mathrm{Ni}_{4}$ layer, $\ell_{s}$ is a representative height for the substrate, and $k_{a i r}, k_{n}$, and $k_{s}$ are the thermal conductivities for their respective layers. Over the bond pads, the layer representing the air gap is removed, and $\ell_{\text {air }}$ is set to zero.

Radiation to the surroundings is negligible at low temperatures. However, for the high temperatures and vacuum environments considered here, it can have an effect. The energy radiated to the surroundings can be expressed as

$$
q_{\text {rad }}=\varepsilon \sigma A_{s}\left[T_{\text {sur }}^{4}-T_{i}^{4}(j)\right]
$$

where $A_{s}$ is the area of the exposed surface of the element.

Conduction of heat between elements, such as between elements $i-1$ and $i$, is modeled by the expression

$$
q_{\text {cond }, i-1}=\frac{k_{p} A_{x}}{\Delta x} \mathbf{T}_{i-1}(j)-T_{i}(j)_{-}^{-}
$$

where $A_{x}$ is the cross-sectional area of the element, $\Delta x$ is the length of the element in the direction of heat transfer and $k_{p}$ is the thermal conductivity of polysilicon. Finally, storage of thermal energy within each element is calculated as

$$
q_{s t}=\frac{\rho c \Delta V_{i}}{\Delta t} \mathbf{T}_{i}(j+1)-T_{i}(j)_{-}^{-}
$$

where $\rho$ and $c$ are the density and specific heat of polysilicon and $\Delta t$ is the time increment. 
By substituting Equations (2) through (8) into Equation (1), an explicit expression for the temperature at time $j+1\left(T_{i}(j+1)\right)$ in terms of temperatures at time $j\left(T_{i}(j), T_{i-1}(j), T_{i+1}(j)\right)$, the input $(J(j))$, and the boundary conditions $\left(T_{\text {sur }}\right.$ and $\left.T_{\text {sub }}\right)$ can be formed:

$$
\begin{array}{r}
T_{i}(j+1)=\frac{\Delta t}{\rho c \Delta V_{i}}\left[J^{2}(j) \rho_{r} \Delta V_{i}+\frac{S A_{u}}{G_{u}} \boldsymbol{\sigma}_{s u b}-T_{i}(j)+\varepsilon \sigma A_{s} \boldsymbol{(}_{s u r}^{4}-T_{i}^{4}(j)\right. \\
\left.\left.+\frac{k_{p} A_{x}}{\Delta x} \boldsymbol{\Gamma}_{i-1}(j)-T_{i}(j)\right]+\frac{k_{p} A_{x}}{\Delta x} \boldsymbol{\sigma}_{i+1}(j)-T_{i}(j)\right] .
\end{array}
$$

By solving the system of difference equations from all of the elements over a series of time increments, a profile of temperatures throughout the device versus time can be produced. With the initial conditions, boundary conditions, and parameter values specified, temperatures for each of the elements at subsequent time steps can be easily calculated. Parameter values used with the model are tabulated in the Appendix. Although subject to stability requirements, the explicit formulation was chosen over an implicit approach because of the desire for a fine resolution in the time step in order to study transient heating. This choice eliminates the need for repeated matrix inversion and back substitution, and allows easy updates of material properties that change with temperature [15].

Simulations were based on a base TIM design with a leg length of $250 \mu \mathrm{m}$ and shuttle dimensions of $50 \mu \mathrm{m}$ by $30 \mu \mathrm{m}$. Laminate beams from MUMPs poly1 and poly2 were also used to create beams $3 \mu \mathrm{m}$ wide and $3.5 \mu \mathrm{m}$ tall. The laminate beams have the advantage of being stiffer out-of-plane, or normal to the substrate, helping prevent out-ofplane buckling from an applied force. The boundary conditions applied to the TIM model assume that the temperatures below the anchored bond pads, $T_{s u b \text {, and the }}$ surrounding temperature, $T_{\text {sur }}$, remain constant at $20{ }^{\circ} \mathrm{C}$. For the leg lengths considered here, this approximation is reasonable; however, for legs with very short lengths, significant heating at the bond pads can occur, and its effect on the boundary condition should be considered [16]. To be thorough, the thermal effects of the bond pads were included by incorporating $100 \mu \mathrm{m}$ long by $30 \mu \mathrm{m}$ wide bond pads into the model at each 
end of the leg-pair. The pads were heated only by conduction from the adjoining legs; the heat generation term from Equation (2) was not included for bond-pad elements. Each leg was divided into 25 elements of equal length. Based on well-established criteria, a constant time step of $1 \mu$ s was used to ensure stability for the selected element size [15].

For validation purposes, simulation results from the finite-difference model are compared to those obtained from an analytical expression modeling the TIM under steady-state conditions. In steady-state, a balance between all energy rates on a differential element requires that resistive heating power generated within the element be equal to heat conducted out. Ignoring radiation and free convection, the following expression results [17]

$$
\frac{\partial}{\partial x}\left(k_{p} \frac{\partial T}{\partial x}\right)+\dot{q}-S \frac{\boldsymbol{\Gamma}-T_{s}}{G_{u} \ell}=0 .
$$

Here, $\dot{q}$ is the rate of energy generation per unit volume due to ohmic heating. This equation has a closed-form solution that describes the temperature versus position along the leg. The solution to this equation for the TIM device is described fully in Ref. [18].

\section{MODELING RESULTS}

The material properties of a TIM are dependent on temperature. Using the finitedifference model, the relative importance of temperature dependencies for various parameters can be examined. This paper presents results for the following cases: (1) constant $k_{p}$, constant $k_{\text {air }}$, where both $k_{p}$ and $k_{\text {air }}$ are modeled as being independent of temperature; (2) constant $k_{p}$, temperature-dependent $k_{\text {air }}$, where $k_{\text {air }}$ varies with temperature while $k_{p}$ remains constant; and (3) temperature-dependent $k_{p}$, temperaturedependent $k_{\text {air }}$, where the temperature dependence of both $k_{p}$ and $k_{\text {air }}$ is modeled. A linear expression for resistivity as a function of temperature is used in all three cases. Case 1 is similar to the model of Equation (10), where constant values for $k_{p}$ and $k_{\text {air }}$ are necessary to make the solution of the differential equation tractable, but the effects of radiation have been included. Cases 2 and 3 allow $k_{\text {air }}$ to vary with temperature. The thermal conductivity of air and its dependence on temperature is well known and is published in 
tables within most heat transfer texts. Using tabulated values from Holman [15], a linear expression relating $k_{\text {air }}$ and temperature was developed. Since the thermal conductivity of a gas is strongly dependent on temperature, the effect is large. The temperaturedependent $k_{\text {air }}$ value is calculated using a temperature that is the average of the element temperature and the substrate temperature. Case 3 uses the temperature-dependent expression for $k_{p}$ from Manginell [19]. This expression varies over the range for which it was measured ( $293 \mathrm{~K}$ to $800 \mathrm{~K}$ ) from $72 \mathrm{~W} / \mathrm{m} / \mathrm{K}$ to $32 \mathrm{~W} / \mathrm{m} / \mathrm{K}$. Expressions for $k_{p}$ and $k_{\text {air }}$ are tabulated in the Appendix.

With polysilicon, the scattering mechanisms that lead to a temperature dependence of thermal conductivity include grain size and dopant concentration, which depend on the deposition method. Smaller grain sizes and higher dopant concentrations are expected to flatten the temperature dependence curve for $k_{p}$ [19]. Because of this, assuming a constant value for $k_{p}$ may be reasonable with smaller grain sizes and high dopant concentrations (on the order of $10^{20}$ atoms $/ \mathrm{cm}^{3}$ ). A constant value of $32 \mathrm{~W} / \mathrm{m} / \mathrm{K}$ [20] has been used previously with MUMPs polysilicon [21] and is used here in Cases 1 and 2.

\section{Temperature profile}

Figure 3 shows the steady-state temperature profiles obtained for a two-leg TIM in air with a constant current input of $5.0 \mathrm{~mA}$. Locations 0 to $100 \mu \mathrm{m}(650$ to $750 \mu \mathrm{m})$ correspond to the bond pad, locations 100 to $350 \mu \mathrm{m}$ (400 to $650 \mu \mathrm{m}$ ) correspond to the leg, and locations 350 to $400 \mu \mathrm{m}$ correspond to the shuttle. From the profiles, it is clear that the analytical solution from Equation (10) and the constant $k_{p}$, constant $k_{\text {air }}$ solution are in good agreement as expected. Since the finite-difference model includes radiation to the surroundings, its temperature profile is slightly lower (2.3 percent at the peak temperatures). The temperature of the shuttle is significantly lower than the legs, for two reasons: First, the heat generation rate is lower due to the lower current density in the shuttle. Second, because of the relatively large surface area of the shuttle, heat is conducted efficiently through the air from the shuttle to the substrate. 


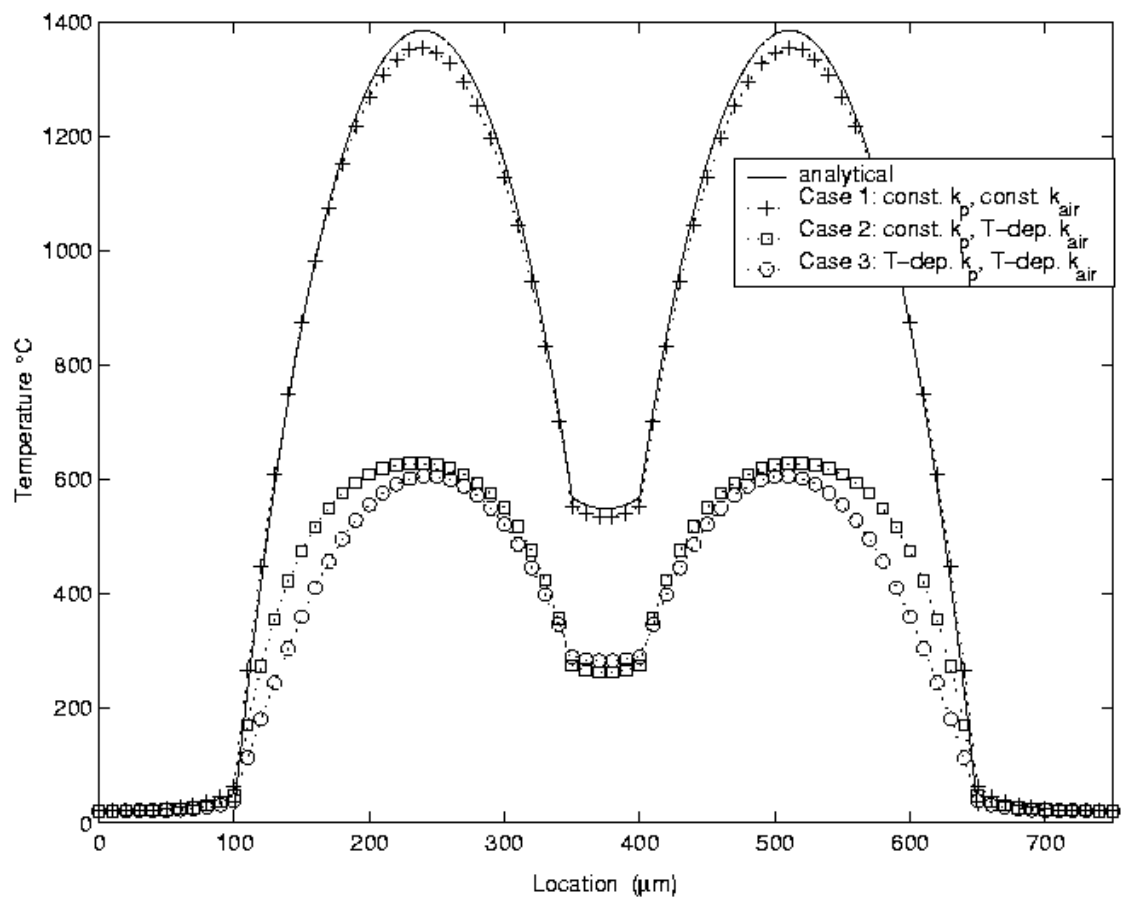

Figure 3: Steady-state temperature profile in air at $5.0 \mathrm{~mA}$.

Steady-state voltages: Case 1: 18.3 V; Case 2: 13.8 V; Case 3: 12.6 V.

Comparison of the constant $k_{p}$, temperature-dependent $k_{\text {air }}$ (Case 2) and temperaturedependent $k_{p}$, temperature-dependent $k_{\text {air }}$ (Case 3) model results indicates that the temperature dependency of the thermal conductivity of polysilicon is not a dominant factor. The lower steady-state temperatures near the bond pads, however, result from the difference in $k_{p}$ values between the models at lower temperatures. At higher temperatures, the thermal conductivity values are nearly the same. Because the resistivity of the polysilicon was modeled as being sensitive to temperature variations, the steadystate voltages resulting from a constant current input varied between the different cases.

The largest effect of any one parameter on the model behavior is the thermal conductivity of air. This can be seen by comparing the results from Cases 1 and 2 in Figure 3, where the only difference in the models is the temperature dependence of $k_{\text {air }}$ included in Case 2. The thermal conductivity of gases is strongly temperature-dependent; and because $k_{\text {air }}$ increases with temperature, there is more heat flow to the substrate, resulting in lower temperatures in the TIM. Based on a peak temperature drop of 46 percent from the 
constant-coefficient model, the results from Figure 3 demonstrate that modeling conduction through the air to the substrate using a temperature-dependent coefficient significantly alters the simulated temperature profile in the TIM.

From Figure 3, it is clear that decreasing the heat conduction through the air to the environment will increase the temperature in the TIM. Insulating the TIM can make heating more efficient. This observation motivated the modeling of the thermal behavior of the TIM in a vacuum environment. As Figure 4 shows, the temperature profiles for the TIM are noticeably different in a vacuum. Because no heat is conducted to the substrate in a vacuum (which is the primary heat transfer method in air), the shuttle temperature rises and eventually becomes the highest temperature in the actuator.

To simulate the vacuum environment, the $q_{c o n d}$ term in Equation (1) (which represents heat conduction down to the substrate) was eliminated from the model. This has the effect of insulating the TIM, leaving conduction through the legs to the bond pads and radiation of heat to the surroundings as the only paths for heat flow. With this insulating effect, the TIM in the vacuum reaches steady-state peak temperatures greater than $600{ }^{\circ} \mathrm{C}$ with a much lower input current. Comparing the temperature-dependent model results from Figures 3 and 4 shows that in a vacuum, an input current of $1.4 \mathrm{~mA}$ causes a peak temperature the same as $5.0 \mathrm{~mA}$ in air. Since actuator displacement increases with leg temperature, this indicates that TIM devices can be operated with much lower steadystate power in a vacuum.

For the $1.4 \mathrm{~mA}$ vacuum results shown in Figure 4, the difference between the constant- $k_{p}$ model and the temperature-dependent- $k_{p}$ model is more pronounced than in air at $5.0 \mathrm{~mA}$. For slightly higher currents, this difference in temperature profiles decreases as the legs become hotter, and the difference in the $k_{p}$ values between the two models is much smaller. For example, at $1.5 \mathrm{~mA}$, the peak temperatures between the two models differ only by 22 percent. 


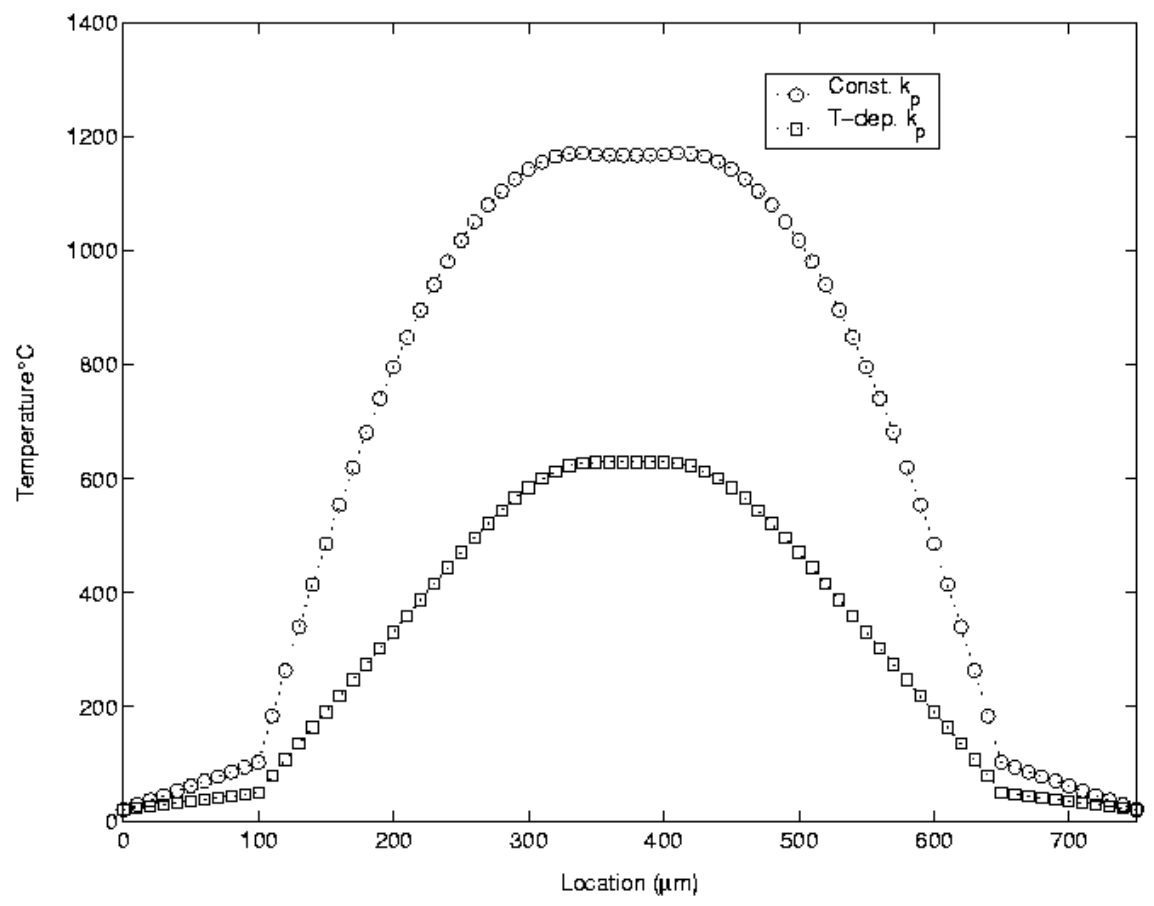

Figure 4: Steady-state temperature profile in vacuum at $1.4 \mathrm{~mA}$.

Steady-state voltages: Constant $k_{p}: 4.59 \mathrm{~V}$; Temperature-dependent $k_{p}: 3.34 \mathrm{~V}$.

A difference between the temperature profiles in air and vacuum can also be seen at the bond pads. In air, the temperature in the pads does not deviate significantly from the substrate temperature at $20{ }^{\circ} \mathrm{C}$. This supports the assumption that the temperatures at the ends of the actuator are equal to the ambient temperature during the heating process. In a vacuum, there is an increase in temperature at the point where the leg meets the contact pad. In Figure 4, the temperature rise is $30^{\circ} \mathrm{C}$ at this location. This increase in temperature is small enough to support the assumption of a constant-temperature boundary condition for the underlying substrate.

\section{MODEL VALIDATION}

Because of the difficulty in measuring temperatures directly from a TIM device, indirect approaches were used to validate the model. The first approach involved using the nodal temperatures from the model as inputs to a commercial finite-element code (ANSYS 5.5) to predict the steady-state shuttle deflection and then comparing this with the shuttle 
deflection measured experimentally under the same conditions. A second validation approach involved photographing the TIM at specific current inputs and looking for two results: the onset and location of visible radiation or the beginning of a small glow, and the charring or destruction of the legs at the melting temperature.

Figures 5 and 6 show how experimental measurements of deflection compare with values calculated from a nonlinear ANSYS model. Figure 5 represents the average of four tests on five different actuators in air; Figure 6 is the average of four tests on two different actuators in a high vacuum $\left(1 \times 10^{-5}\right.$ torr $)$. Error bars represent one standard deviation. Model predictions were made with each of the cases discussed above. In this manner, the importance of temperature dependencies for the thermal conductivity parameters is examined.

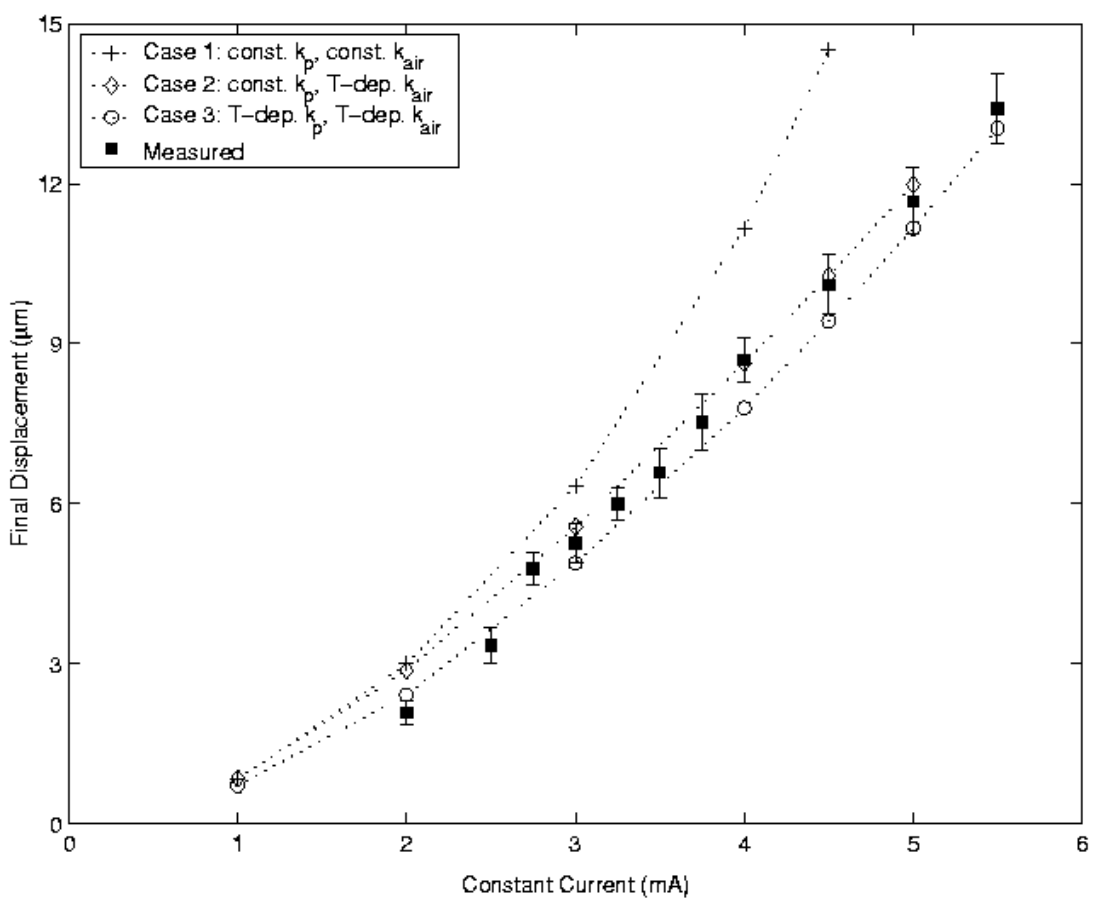

Figure 5: Shuttle displacement versus current, in air.

As Figure 5 shows, a good fit to the data from in-air tests is obtained by using values for $k_{p}$ and $k_{\text {air }}$ that depend on temperature. This result is also seen for the vacuum results in Figure 6. In a vacuum, the deviation of the model at higher currents is believed to be the 
result of self-annealing and localized melting at the grain boundaries. At these currents, temperatures are sufficient to cause secondary breakdown in the polysilicon [22]. The secondary breakdown causes a resistance decrease that can be explained in terms of a segregation of impurity atoms in the subsequent solidification process [23]. This deviation was also observed for in-air tests beyond the applied current values plotted in Figure 5.

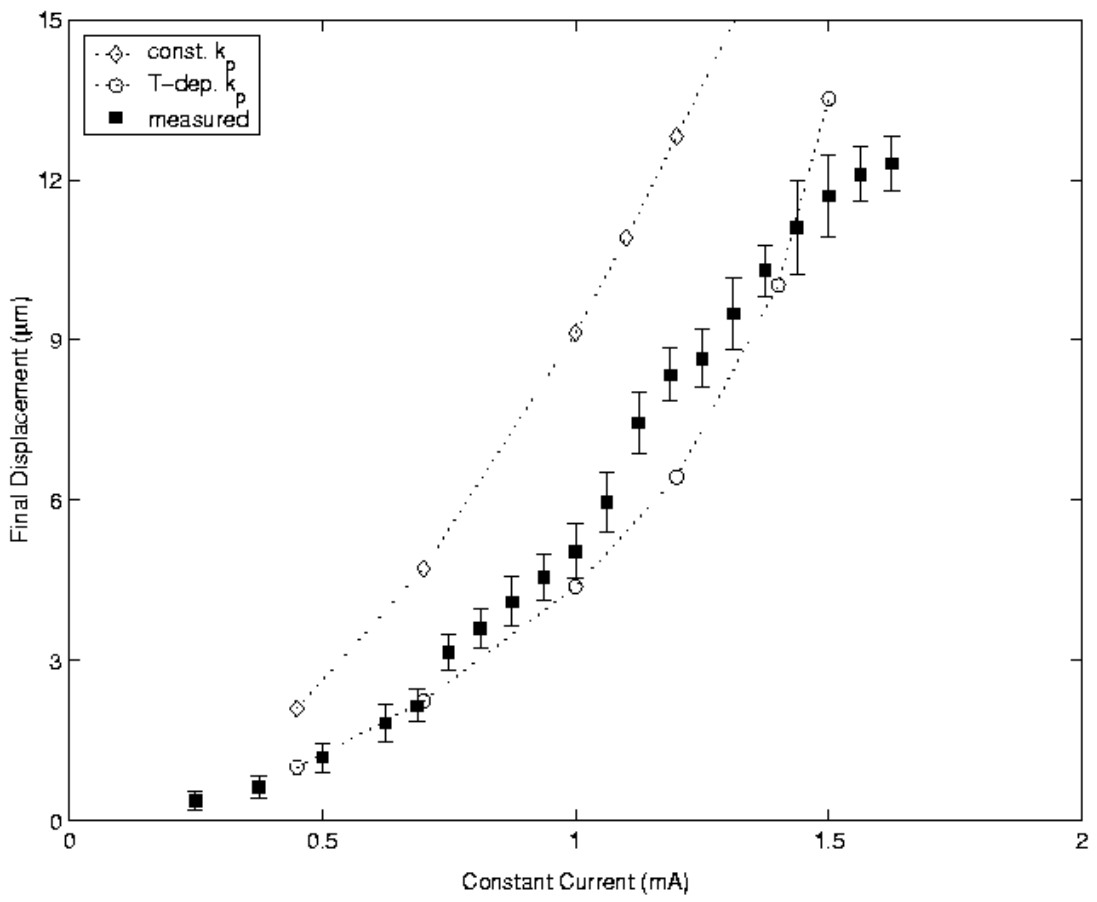

Figure 6: Shuttle displacement versus current, in vacuum.

Figure 5 also demonstrates the importance of including a temperature-varying $k_{\text {air }}$ parameter. At higher temperatures and displacements, the temperature dependence of the thermal conductivity for air is strong and must be included for accurate model predictions. In Figure 6, where air is not a factor, the model suggests that a constant value for the thermal conductivity of laminate MUMPs polysilicon leads to inaccuracies for temperature and displacement predictions. In air, however, the inaccuracy is masked by the more dominant effect of the temperature-dependent $k_{\text {air }}$ parameter. 
Figure 7 shows an array of video frames captured with slightly increasing current loads. Only half of the TIM is shown due to symmetry. From left to right, the currents imposed across each leg of the TIM are $5.75 \mathrm{~mA}, 6 \mathrm{~mA}, 6.5 \mathrm{~mA}$, and $7 \mathrm{~mA}$. The first frame offers support for the use of a temperature-dependent- $k_{\text {air }}$ model. The model predicts that the small glow seen at $5.75 \mathrm{~mA}$ has a peak temperature of $864{ }^{\circ} \mathrm{C}$, while the constant- $k_{\text {air }}$ model predicts peak temperatures beyond the melting temperature $\left(1411^{\circ} \mathrm{C}\right)$. This supports the inclusion of a temperature-dependent $k_{\text {air }}$ expression for more accurate modeling. In the last frame at $7 \mathrm{~mA}$, the temperature predicted by the temperaturedependent-conductivity model is $1431{ }^{\circ} \mathrm{C}$, which is beyond the melting point of polysilicon. As discussed before, some modeling discrepancies near the melting temperature are expected due to secondary breakdown of the polysilicon. In the experiment, the legs were destroyed upon increasing the current in the legs to $7.25 \mathrm{~mA}$. These observations provide further validation of the correctness of the model.

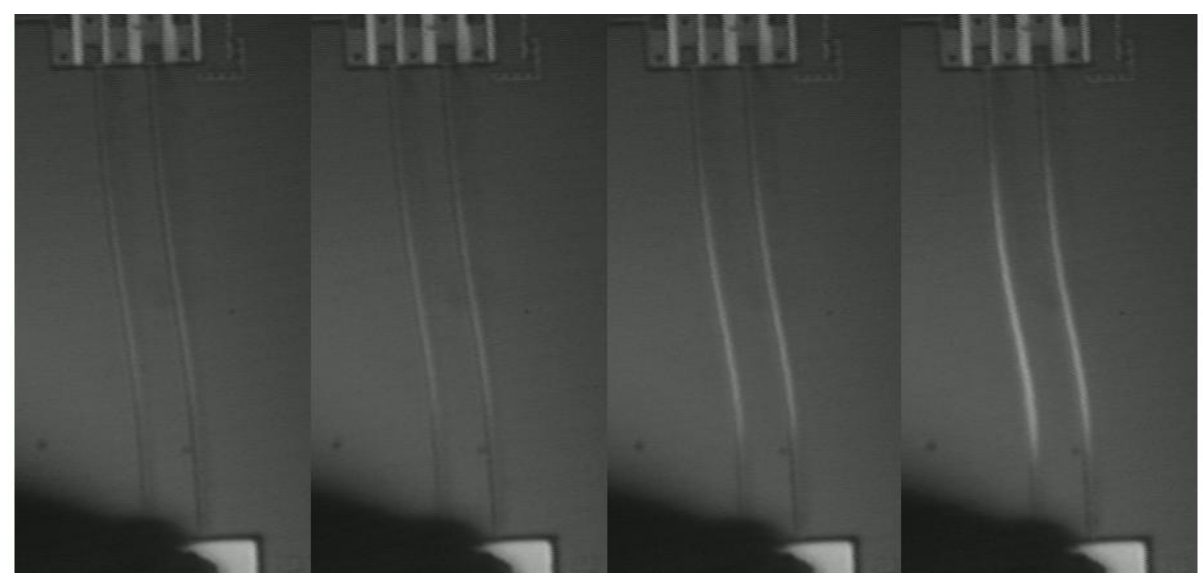

Figure 7: Images of TIM legs with increasing currents applied. From left to right the applied current per leg is $5.75 \mathrm{~mA}, 6 \mathrm{~mA}, 6.5 \mathrm{~mA}$, and $7 \mathrm{~mA}$.

\section{MODEL-BASED PERFORMANCE PREDICTIONS}

Transient temperature response

The different paths available for heat transfer between air and vacuum also affect the temperature response time of the TIM. Because the temperature-dependent model matches experimental results most accurately, it was used to generate the simulation results discussed subsequently. The model results of Figure 8 show that for a constantcurrent input, the average leg temperature in a vacuum rises to the same average 
temperature approximately 30 times slower than in air. Simulation studies show this to be true as long as inputs currents are chosen for each environment so that the steady-state average leg temperatures are the same.
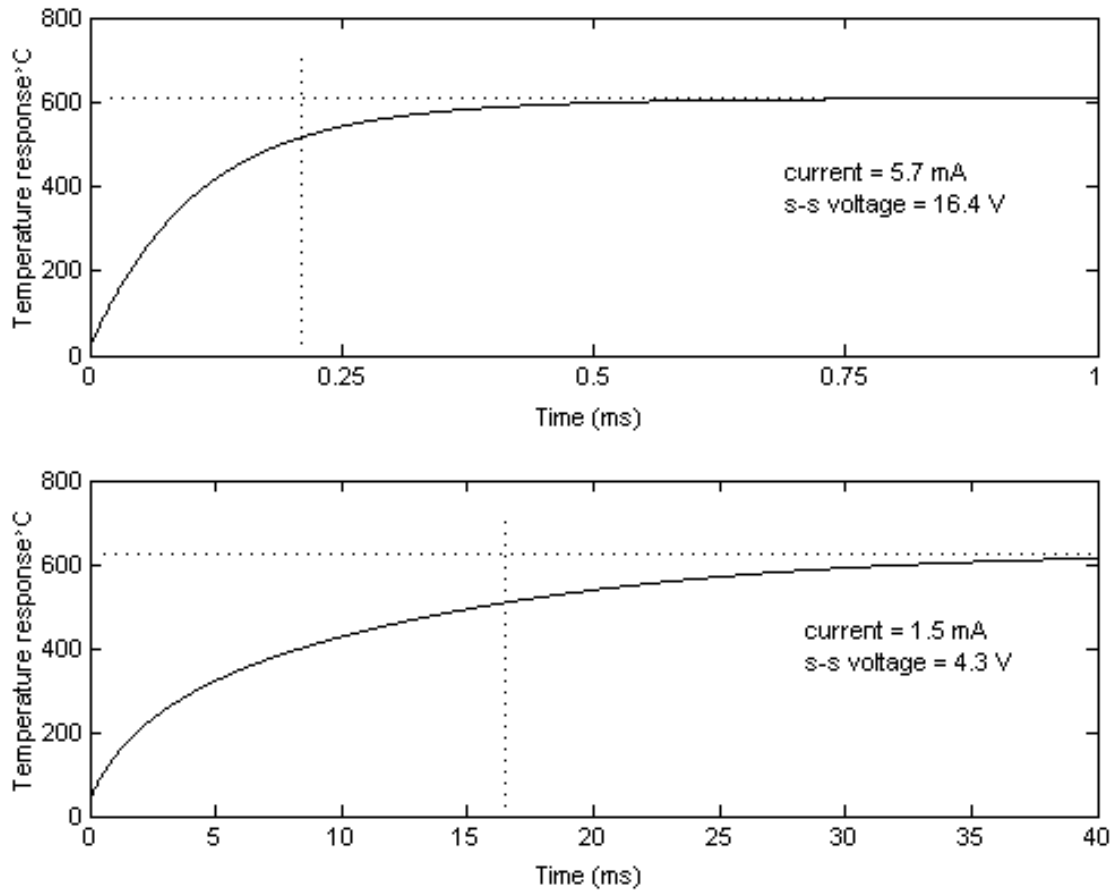

Figure 8: Temperature response of legs in air (top), and response of legs in a high vacuum (bottom) as simulated with the temperature-dependent conduction coefficients.

For equivalent steady-state leg temperatures, the transient response in a vacuum is slower than in air for two reasons: First, since less current is required in a vacuum to reach the desired steady-state temperature, less power is applied, which reduces the rate at which the legs heat up. Second, the temperature transient response is slower because the center shuttle on the TIM acts as a large thermal capacitance. Physically, this slows down the speed at which the average leg temperature can rise. When there is no conduction through the air to the substrate, all heat loss is either through radiation to the environment or is conducted axially out through the anchored bond pads. With a shuttle that is large (relative to the size of the legs) and the removal of conduction to the substrate, the effective system time constant for transient response is increased significantly in a vacuum. 
The results of Figure 8 indicate that steady-state temperatures are reached in air in about $1 \mathrm{~ms}$. This result is supported by previous experimental measurements of the transient response of the TIM [10], which used a high-speed camera to record motion at $1000 \mathrm{~Hz}$ and indicated that the final deflection was consistently stable within two frames.

While the effective time constant is larger in the vacuum than in air, the device is insulated in a vacuum, which results in much lower heat loss to the environment. For an equivalent current input, the device in the vacuum will reach a much higher steady-state temperature than in air. Figure 9 shows the temperature response of the TIM in air and vacuum for a $5.7 \mathrm{~mA}$ current step input. Although the TIM in the vacuum would melt before reaching a steady-state temperature, the shape of the transient response curves confirms that the vacuum-based TIM has a slower time constant. Even so, the TIM in the vacuum reaches $600{ }^{\circ} \mathrm{C}$ in significantly less time than the TIM in air. This demonstrates that for an equivalent step input magnitude, the time required for the TIM in the vacuum to heat up is not necessarily slower than the TIM in air. Because $5.7 \mathrm{~mA}$ is sufficiently large to cause melting of the TIM in a vacuum, safe operation of the TIM requires that the step input be turned off before melting occurs. This implies that comparably fast responses from the TIM in a vacuum can be obtained provided that short-duration, highcurrent pulses (rather than step inputs) can be provided. 


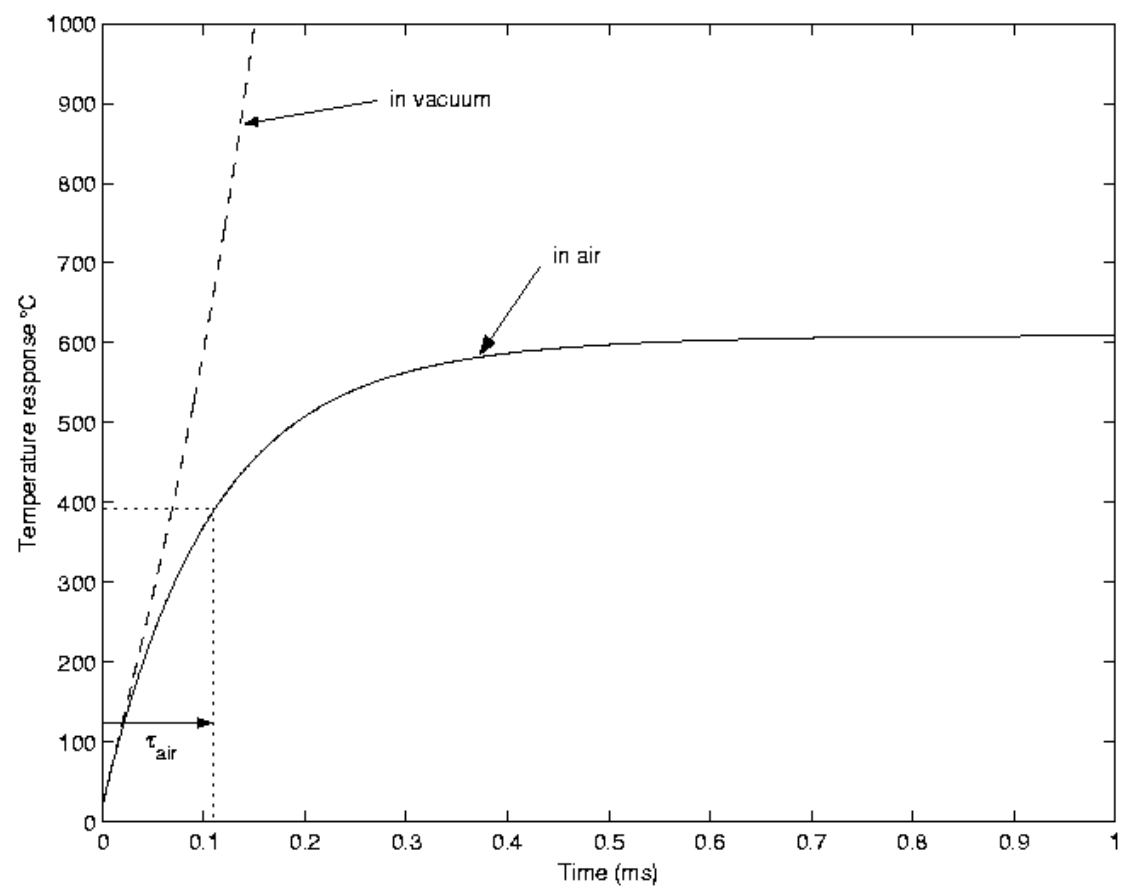

Figure 9: Average leg temperature response of TIM in air and in vacuum for a $5.7 \mathrm{~mA}$ step input.

\section{Power draw and energy consumption}

The power demands at steady state, and the energy required to change the temperature in the actuator, are important performance criteria for thermal actuators. In this study, the energy required during transient response was calculated by integrating the instantaneous power provided to the TIM in response to a step input in current. The integration was carried out from the time the step input was applied until the time when the transient was 90 percent complete. The dotted vertical line in Figure 8 represents the amount of time elapsed to reach 90 percent of the final average temperature. This rise time was $0.22 \mathrm{~ms}$ for air and $16 \mathrm{~ms}$ under vacuum. Because less current is required in a vacuum to maintain the steady-state leg temperature of the TIM, significantly lower steady-state power is needed to obtain the same average temperature rise in the expansion legs. For the responses shown in Figure 8, 87.8 $\mathrm{mW}$ was required in air versus $6.4 \mathrm{~mW}$ in a high vacuum. However, because the transient was slower in the vacuum, over five times the amount of total energy was consumed to reach a steady temperature profile in vacuum than for the temperature transient in air $(15.4 \mu \mathrm{J}$ versus $85.4 \mu \mathrm{J})$. 

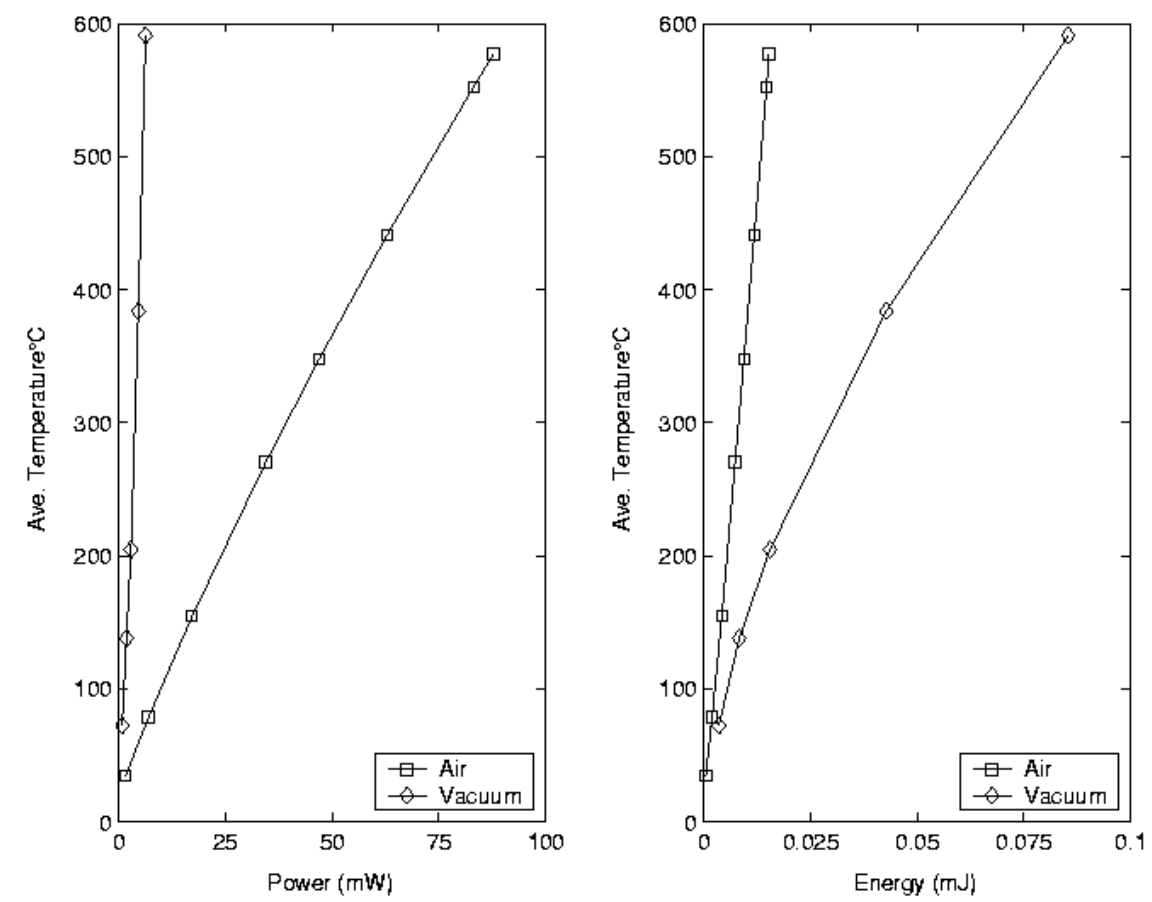

Figure 10: Power required to hold a steady-state temperature (left) and energy required to reach a steady-state temperature (right) with a constant-current input.

Figure 10 shows the steady-state power consumption for the TIM in air and vacuum with a constant-current input. Over a broad range of operating temperatures, the TIM requires less steady-state power when operating in a vacuum. This is especially true at higher leg temperatures (i.e., larger shuttle displacements). Figure 10 also shows the energy consumed during the transient to steady state for the TIM in air and vacuum with a constant-current input. Over the range of temperatures simulated, the TIM operated in a vacuum requires more energy to reach a specified leg temperature than a TIM operating in air as long as constant-current inputs are used. This is due primarily to the slower transient response of the TIM in the vacuum when low-level currents are applied. Because there is less heat loss to the environment in the vacuum, the potential for improved transient response and energy efficiency of the TIM exists if different types of inputs are applied. 


\section{Pulse Simulations}

By providing short duration current pulses to the device in a vacuum, improved transient response and energy efficiency can be achieved. To test this assertion, the model was adjusted to give high current pulses to the TIM to study the result on energy consumed. In the model, the $q_{i}$ term was activated for $0.1 \mathrm{msec}$ with a current input of $5.7 \mathrm{~mA}$. A steady application of this level of current in a vacuum would normally heat the TIM past its melting temperature, but for this duration it brings the TIM to a peak temperature of $908{ }^{\circ} \mathrm{C}$. Figure 11 shows the result of this simulation. Notice that the shuttle does not have sufficient time to climb to a high temperature and that the highest temperatures occur in the more useful area of the legs, where thermal expansion is desired. This increases the average temperature in the legs and results in greater deflection at this peak temperature than is achieved with a constant current. Furthermore, as Figure 11 shows, the speed of the transient response increases significantly over the constant-current response of Figure 8. This suggests that the actuator would be suitable for switching tasks where a fast rise time is important, provided that short, high-current pulses are used. Since the applied current must be removed before melting temperatures are reached, the TIM does not reach a steady-state temperature profile. Under these conditions, the TIM required only $7.3 \mu \mathrm{J}$ of energy to go through the same average temperature transient shown in Figure 8. The same temperature transient required $15.4 \mu \mathrm{J}$ of energy in air. 

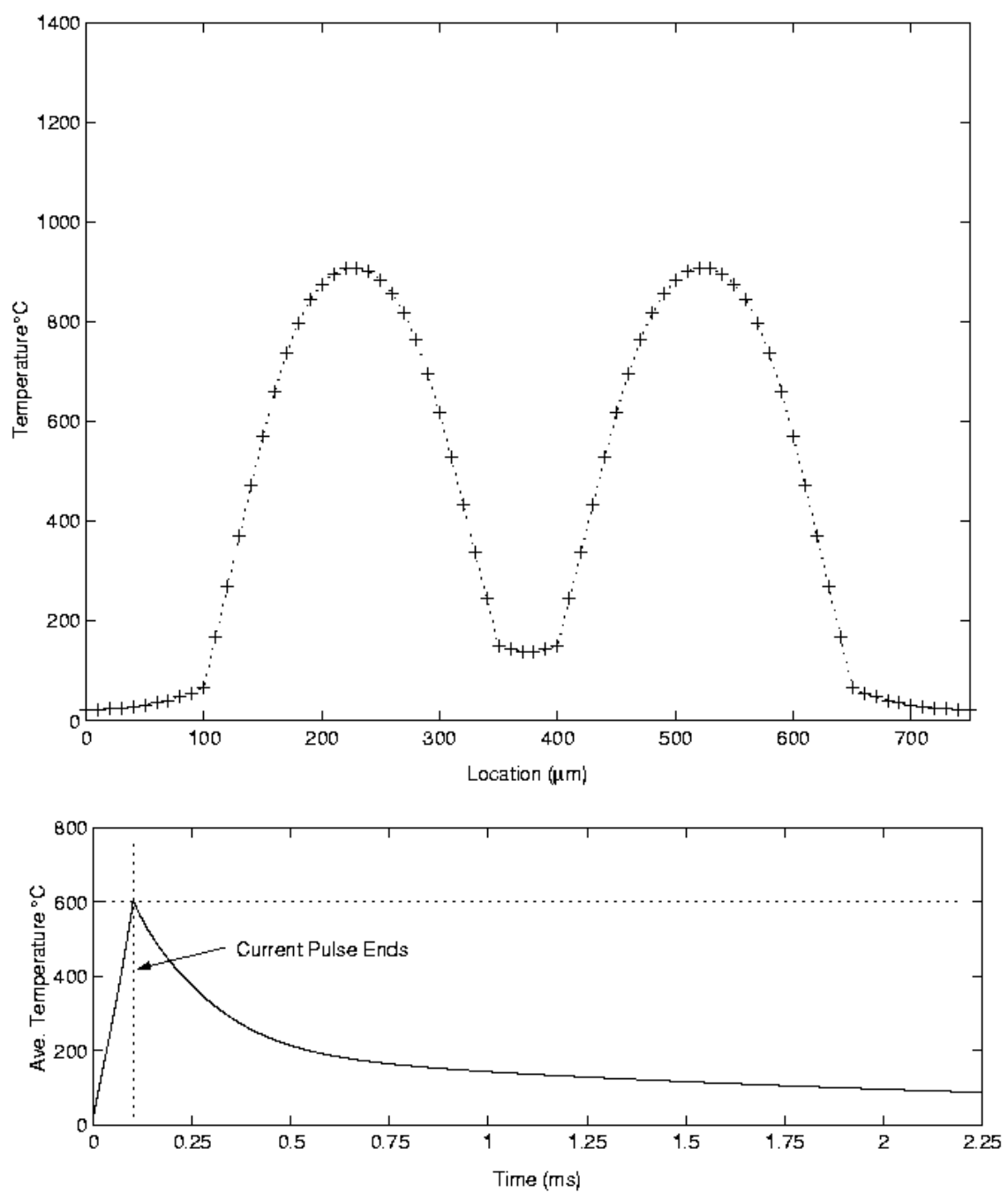

Figure 11: Steady-state temperature profile (top) and transient heating response (bottom) of a TIM pulsed in a vacuum.

\section{CONCLUSIONS}

A finite-difference model for a thermomechanical in-plane microactuator has been developed. Comparisons between model results and experimental results support the use of temperature-dependent values for the thermal conductivity of polysilicon and air in the model. Based on insights from the model, operation of the TIM in a vacuum environment was investigated. Experimental results showed that equivalent steady-state deflections in a vacuum required significantly less current than in air. Using the model, the performance characteristics of the TIM, such as its transient response and power 
consumption can be predicted. Simulations with the model suggest that the TIM is most energy efficient when operated in a vacuum with short-duration, high-current inputs.

\section{REFERENCES}

[1] P.E. Kladitis and V.M. Bright, Prototype microrobots for micro-positioning and micro-unmanned vehicles, Sensors and Actuators A, 80 (2000) 132-137

[2] H. Guckel, J. Klein, T. Christenson, K. Skrobis, M. Laudon, and E.G. Lovell, Thermo-magnetic metal flexure actuators, Proc. of the $5^{\text {th }}$ IEEE Solid-State Sensor and Actuator Workshop, (1992), 73-75

[3] J.H. Comtois, V.M. Bright, and M.W. Phipps, Thermal microactuators for surfacemicromachining processes, SPIE, 2642 (1995) 10-21

[4] N.D. Mankame and G.K. Ananthasuresh, Comprehensive thermal modeling and characterization of an electro-thermal-compliant microactuator, Journal of Micromechanics and Microengineering, 11 (2001) 452-462.

[5] T. Moulton and G.K. Ananthasuresh, Micromechanical devices with embedded electro-thermal-compliant actuation, Sensors and Actuators A, 90 (2001) 38-48

[6] L. Que, J.-S. Park, and Y.B.Gianchiandani, Bent-beam electrothermal actuatorsPart I: Single beam and cascaded devices, Journal of Microelectromechanical Systems, Vol. 63, No. 5, (2001), 247-254

[7] J.-S. Park, L.L. Chu, A.D. Oliver, and Y.B. Gianchandani, Bent-beam electrothermal actuators - Part II: Linear and rotary microengines, Journal of Microelectromechanical Systems, Vol. 63, No. 5, (2001), 255-262

[8] O. Sigmund, Design of multiphysics actuators using topology optimization - Part I: One-material structures, Computer Methods in Applied Mechanics and Engineering, Vol. 190, No. 49-50, (2001) 6577-6604

[9] J. Jonsmann, O. Sigmund, and S. Bouwstra, Compliant electro-thermal microactuators, Proc. of the IEEE Micro Electro Mechanical Systems (MEMS), (1999) 588-593

[10] R. Cragun. and L.L. Howell, Linear thermomechancial microactuators, Proc. ASME IMECE MEMS (1999) 181-188

[11] MUMPS Program Overview, http://www.memsrus.com/cronos/svcsmumps.html

[12] L. Lin and M. Chiao, Electrothermal responses of lineshape microstructures, Sensors and Actuators A, 55 (1996) 35-41

[13] L. Lin, A.P. Pisano, and V.P. Carey, Thermal bubble formulation on polysilicon micro resistors, Journal of Heat Transfer, 120 (1998) 735-742

[14] L. Lin, and A.P. Pisano, Bubble forming on a micro line heater, ASME DSCVol. 32, Micromechanical Sensors, Actuators, and Systems, 1991

[15] J.P. Holman, Heat Transfer, $8^{\text {th }}$ Ed., McGraw-Hill, 1997

[16] G.K. Fedder, and R.T. Howe, Thermal assembly of polysilicon microstructures, Proc. of IEEE Micro-Electro-Mechanical Systems Workshop, (1991) 63-68

[17] Q. Huang, and N. Lee, Analysis and design of polysilicon thermal flexure actuator, Journal of Micromechanics and Microengineering, 9 (1999) 64-70

[18] C.D. Lott, Electrothermomechanical modeling of a surface-micromachined linear displacement microactuator, M.S. Thesis, Brigham Young University, 2001. 
[19] R. Manginell,1997, Polycrystalline-silicon microbridge combustible gas sensor, Ph.D. Dissertation, Univ. of New Mexico, 1997

[20] Y.C. Tai, C.H. Mastrangelo, and R.S. Muller, Thermal conductivity of heavily doped low-pressure chemical vapor deposited polycrystalline silicon films," Journal of Applied Physics, Vol. 63, No. 5 (1998) 1442-1447

[21] J. Butler and V. Bright, Electrothermal and fabrication modeling of polysilicon thermal actuators, ASME DSC-Vol. 66, Micro Electro-Mechanical Systems (MEMS), 1998, 571-576

[22] D.W. Greve, Programming mechanism of polysilicon resistor fuses," IEEE Transactions on Electron Devices, Vol. 29, No. 4 (1982) 719-724

[23] K. Kato and T. Ono, A physical mechanism of current-induced resistance decrease in heavily doped polysilicon resistors," IEEE Transactions on Electron Devices, Vol. 29, No. 8, (1982) 1156-1160

[24] C.H. Mastrangelo, Thermal applications of microbridges," Ph.D. Dissertation, Univ. of California, Berkeley, 1991 


\section{APPENDIX}

\begin{tabular}{lll}
\hline \multicolumn{1}{c}{ Parameter } & \multicolumn{1}{c}{ Value } & Ref. \\
\hline $\begin{array}{l}\text { Emissivity of polysilicon } \\
\text { (assumed temp. independent) }\end{array}$ & $\varepsilon=0.6$ & [17] \\
$\begin{array}{l}\text { Thermal cond. of } \mathrm{Si}_{3} \mathrm{Ni}_{4} \\
(293 \mathrm{~K})\end{array}$ & $k_{n}=2.25 \mathrm{~W} / \mathrm{m}^{\circ} \mathrm{C}$ & \\
Thermal cond. of air & $k_{\text {air }}=0.026 \mathrm{~W} / \mathrm{m}^{\circ} \mathrm{C}$
\end{tabular}

